\title{
Modified Sulfonated Glucose-Catalyzed Esterification of Palm Fatty Acid Distillate: Kinetics and Fuel Properties
}

\author{
Haruna Mavakumba Kefas ${ }^{1,2, ~ *, ~ R o b i a h ~ Y u n u s ~}{ }^{2,3}$, Umer Rashid ${ }^{3}$, Yun Hin Taufiq-Yap ${ }^{4,5}$ \\ ${ }^{1}$ Department of Chemical Engineering, Modibbo Adama University of Technology, Yola, Nigeria \\ ${ }^{2}$ Department of Chemical and Environmental Engineering, University Putra Malaysia, Selangor, Malaysia \\ ${ }^{3}$ Malaysia Institute of Advanced Technology, University Putra Malaysia, Selangor, Malaysia \\ ${ }^{4}$ Catalysis Science and Technology Research Centre, University Putra Malaysia, Selangor, Malaysia \\ ${ }^{5}$ Department of Chemistry, University Putra Malaysia, Selangor, Malaysia
}

Email address:

hmkefas@gmail.com (H. M. Kefas),robiah@upm.edu.my (R. Yunus)

${ }^{*}$ Corresponding author

\section{To cite this article:}

Haruna Mavakumba Kefas, Robiah Yunus, Umer Rashid, Yun Hin Taufiq-Yap. Modified Sulfonated Glucose-Catalyzed Esterification of Palm Fatty Acid Distillate: Kinetics and Fuel Properties. American Journal of Chemical Engineering. Vol. 8, No. 6, 2020, pp. 131-138. doi: 10.11648/j.ajche.20200806.12

Received: November 11, 2020; Accepted: November 24, 2020; Published: December 16, 2020

\begin{abstract}
The employment of sugar acid catalysts for biodiesel synthesis from non-edible palm fatty acid distillate (PFAD) has received huge research interest in recent times by reason of their stability and high catalytic performance. Notwithstanding, the need to extend research on the kinetic characteristics of these heterogeneous catalysts is important in order to understand their reaction mechanisms. The present investigation deals with the kinetics for the esterification of PFAD by means of modified sulfonated carbonized glucose catalyst to biodiesel in a three necked conventional reflux batch reactor. The efficient catalyst was synthesized by sulfonation of incomplete carbonized glucose. The pseudo-homogeneous first and second order (equimolar) mechanism was utilized to interpret the data at optimum operating conditions of 10:1 molar fraction of methanol to PFAD, $4 \mathrm{~h}$ time of reaction and 4 wt.\% quantity of catalyst at varying reaction temperature of $50-65^{\circ} \mathrm{C}$. Furthermore, some important properties of the PFAD biodiesel produced were assessed utilizing ASTM methods. The experimental data best fitted the bimolecular model (equimolar) second order model. The activation energy was calculated to be $55.08 \mathrm{kJmol}^{-1}$ which indicates that the catalyst was very active in the esterification of the PFAD to biodiesel. Most of the measured fuel properties of the PFAD biodiesel were comparable with the ASTM standards.
\end{abstract}

Keywords: Modified Sulfonated Glucose, Kinetics, Pseudo Homogeneous, Free Fatty Fcids, Biodiesel, Fuel Properties

\section{Introduction}

Free fatty acids (FFA) esterification and triglycerides (TG) transesterification with short chain alcohol like methanol are the key chemical routes for the synthesis of biodiesel also known as methyl esters [1-3]. Due to environmental benefits and origin of renewable resources, biodiesel has been increasingly studied as an effective alternative fuel resource. Biodiesel offers better advantages which include biodegradability, lower emission of $\mathrm{CO}$, better lubrication of engines, less toxic to human and zero sulfur emission compared to conventional diesel [4-6].

Biodiesel production utilizing edible oil as feedstock results in high price of the product compared to the conventional diesel. The cost of edible oil feedstock is known to account for about $60-75 \%$ production cost of the biodiesel fuel [7]. The less cost oils are those that involve high quantity of (FFA) like waste cooking oil, animal fats and a number of non-edible oils. Utilizing low-cost feedstocks for biodiesel production is gaining economic attractiveness [8-10]. Thus, alternative cheaper feedstocks have been investigated and studied in recent times. One of the low-cost feedstock that has gained attention is the palm fatty acid distillate (PFAD).

In 2017, Malaysia and Indonesia were the highest producers of palm oil with the production capacity of 19.2 and 36.5 million metric tons of crude palm oil 
(CPO), respectively [11]. In Malaysia alone, every year about 700,000 metric tons of PFAD are generated from palm oil as by product of the refinning process [12]. PFAD contains about $85-95 \%$ FFA and 5-15\% triglycerides with little quantity of squalene, vitamin E and sterols [13]. The transesterification of PFAD with homogeneous catalysts present some technical issues which comes from costly separations and purification steps. To eliminate these issues the heterogeneous solid acid catalyst has been introduced [14]. Mostly, production of biodiesel using heterogeneous solid catalytic system possess the ability to overcome problems associated with homogeneous system with advantages of being less corrosive, environmentally benign, reusable, and ease of the catalyst removal from the reaction mixture [15]. Heterogeneous acid catalysts have been understood to be excellent in biodiesel synthesis using low-cost oils because of their unique properties especially enhancing esterification plus transesterification reaction thereby overcoming the two step production [16].

The kinetic model studies involving heterogeneous acid catalyzed esterification reaction have been accounted for in literature and could be classified into four major applications based on the system utilized: the pseudo-homogeneous $(\mathrm{PH})$, the Eley-Rideal (ER), the Langmuir-Hinshelwood (LH) and the Popken (PP) models [17]. Among these models, the PH model (second order) has been utilized to describe numerous FFA esterification in the presence of triglyceride [18]. The $\mathrm{PH}$ model is mostly adopted due to its similarity to the homogeneous reaction where no adsorption term is involved in the reactive medium for any species [17]. Rattanaphra et al. [18] reported that the esterification kinetic model of myristic acid mixed with refined rapeseed oil with sulfated zirconia followed the PH model. They further reported a reversible second order PH model to justify the experimental data and the model satisfactorily interpreted the results. Also, Amberlyst-15 a heterogenous catalyst was used in the kinetic model study of the transesterification of methyl stearate by means of n-butanol as a reactant in excess amount [19]. The kinetic data obtained were fitted to a pseudo-homogeneous model.

Many researches have been performed on the utilization of heterogeneous catalytic system to synthesize biodiesel [20-23] but there have been fewer research works to describe the kinetics. Previously, Kefas et al. [24] successfully synthesized and characterized modified sulfonated glucose catalyst which was used for the production of biodiesel from PFAD. However, there was no kinetic study conducted on the employment of the solid catalyst for the esterification of the PFAD. Therefore, this research is aimed at further investigation of the FFA esterification of the PFAD using the synthesiezed catalyst. The research was experimented in a three necked conventional reflux batch reactor to obtain the kinetic data at different temperatures. The esterification was performed at optimized conditions of 10:1 molar fraction of methanol to PFAD and $4 \mathrm{wt} \%$ amount of catalyst over range of time.

\section{Materials and Methods}

\subsection{Materials}

The PFAD utilized for the experiment was obtained from a company, Sime Darby Sdn. Bhd. (Klang Selangor) in Malaysia. The physicochemical properties of the PFAD are shown in Table 1. Commercial d-glucose, ammonium sulfate $\left(\left(\mathrm{NH}_{4}\right)_{2} \mathrm{SO}_{4}\right)$ and hexane were obtained from $\mathrm{R} \& \mathrm{M}$ chemical. Concentrated sulfuric acid $\left(\mathrm{H}_{2} \mathrm{SO}_{4}\right)$, hydrochloric acid (HCI), potassium hydroxide $(\mathrm{KOH})$, ethanol, and sodium hydroxide $(\mathrm{NaOH})$ were bought from fisher scientific. Isopropyl alcohol and methanol were purchased from Systerm Company.

\subsection{Synthesis of Catalyst}

As aforementioned in previous study [24], the catalyst was synthesized by adjustment of the methods reported by Zong et al. [23] and Shuit and Tan [25]. The precusor (incomplete carbonized glucose) was obtained by heating glucose material at $400^{\circ} \mathrm{C}$ for $12 \mathrm{~h}$ under nitogen ambient in a furnance. The carbonized solid was ground to powder and mixed with $11.25 \%\left(\mathrm{NH}_{4}\right)_{2} \mathrm{SO}_{4}$ solution. It was sonicated for $10 \mathrm{~min}$ and sulfonated at $235^{\circ} \mathrm{C}$ for $30 \mathrm{~min}$. To eliminate excess of $\left(\mathrm{NH}_{4}\right)_{2} \mathrm{SO}_{4}$ from the mixture, it was washed with distilled water and dried at $105^{\circ} \mathrm{C}$ for 30 minutes. The dried material was then mixed with concentrated $\mathrm{H}_{2} \mathrm{SO}_{4}(96 \%)$ and sulfonated at $151^{\circ} \mathrm{C}$ temperatue under nitrogen gas flow for $5.34 \mathrm{~h}$. The mixture was washed to remove sulfate ions with distilled water, filtered and oven dried at $105^{\circ} \mathrm{C}$ for $12 \mathrm{~h}$.

Table 1. Physical and chemical properties of the PFAD utilized [24].

\begin{tabular}{lll}
\hline Properties & PFAD & Methods \\
\hline FFA content $(\%)$ & 90.04 & AOCS Ca 5a-40 \\
Iodine value, $\left(\mathrm{gI}_{2}\right) \cdot(100 \mathrm{~g})^{-1}$ & 54.60 & AOCS Cd 1-25 \\
Conventional mass pervolume at $50^{\circ} \mathrm{C}\left(\mathrm{kg} \cdot \mathrm{L}^{-1}\right)$ & 0.8875 & \\
Saponification value $(\mathrm{mg} \mathrm{KOH}) \cdot(\mathrm{g} \mathrm{sample})^{-1}$ & 205.68 & AOCSCd 3-25 \\
Moisture content $(\%)$ & 0.11 & AOCS Aa 3-38 \\
Composition of fatty acid $(\mathrm{wt} \%)$ & & \\
$\mathrm{C}_{12: 0}$ (Lauric acid) & 0.04 & \\
$\mathrm{C}_{14: 0}$ (Myristic acid) & 1.26 & \\
$\mathrm{C}_{16: 0}$ (Palmitic acid) & 51.64 & \\
$\mathrm{C}_{18: 0}$ (Stearic acid) & 4.17 & \\
$\mathrm{C}_{18: 1}$ (Oleic acid) & 36.43 & \\
$\mathrm{C}_{18: 2}$ (Linoleic acid) & 6.46 & \\
\hline
\end{tabular}

\subsection{PFAD Esterification}

The PFAD esterification with glucose acid catalyst was done utilizing three necked conventional reflux reactor (Figure 1). The feedstock was first melted by heating in the oven at $80^{\circ} \mathrm{C}$ and then measured quantity was transferred into the batch reactor. Required amount of methanol and catalyst were also introduced into the reactor and was heated to the required temperature for reaction to commence. Operating parameters for instance weight of catalyst in the range of 1-7 $\mathrm{wt} \%$, molar fraction of methanol to PFAD in the range of $5: 1-12: 1$, temperature in the range of $45-70^{\circ} \mathrm{C}$, and time of reaction in the range of $1-7 \mathrm{~h}$ were investigated and results reported in previous research [24] 


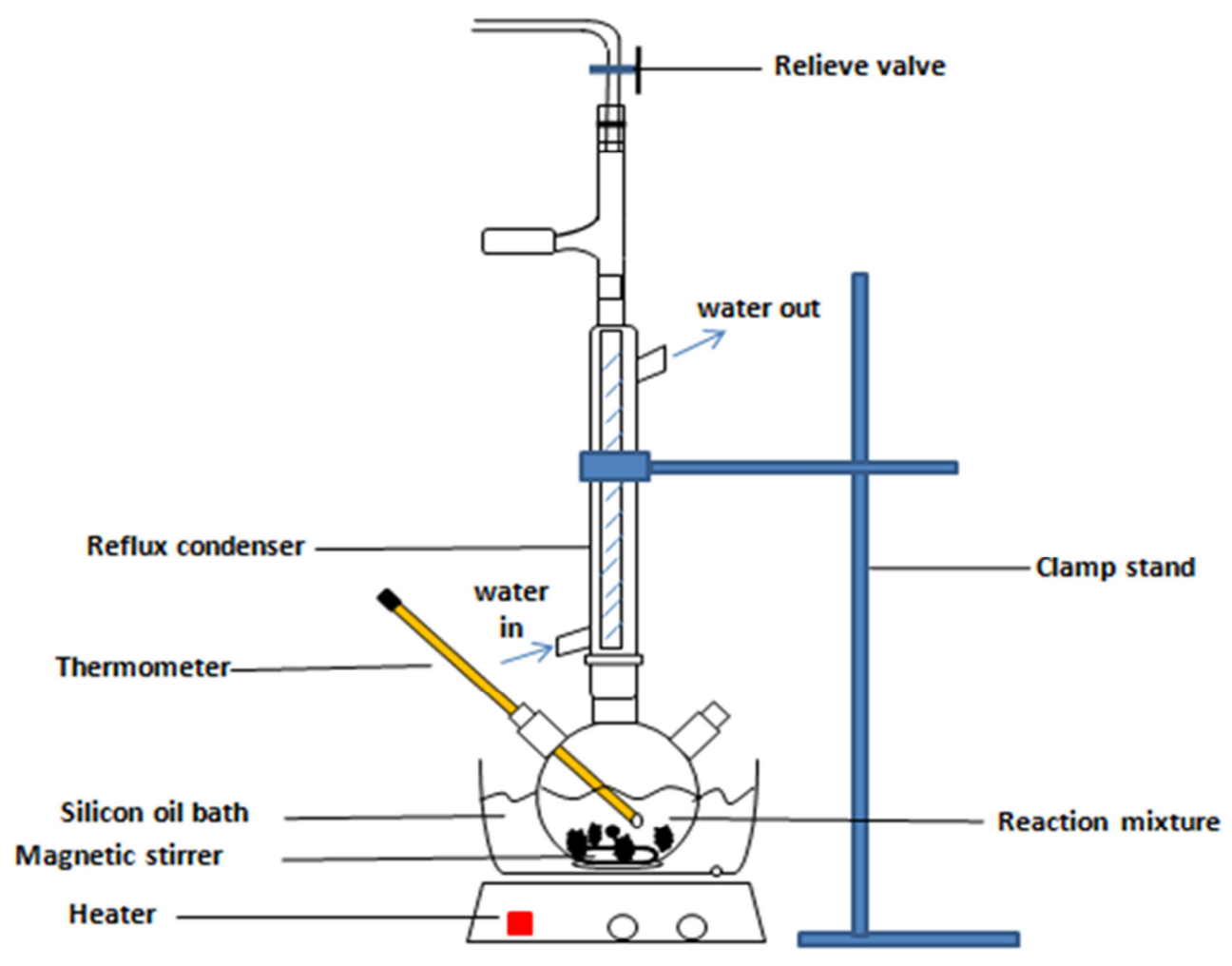

Figure 1. Schematic diagram of batch reflux reactor utilized for the synthesis of PFAD biodiesel and kinetic studies.

\subsection{Kinetic Experiment of the Esterification Reaction}

The kinetics was performed to detemine the reaction rate, order of reaction, rate constant and also the activation energy (Ea) required for converting FFA to biodiesel. As mentioned previously, The kinetic work for the esterification was done optimized operating conditions of 10:1 m, $4 \mathrm{~h}$ time, 4 wt.\% catalyst load, and $600 \mathrm{rpm}$ stirring speed in a three neck conventional reflux batch reactor (Figure 1) with varied reaction temperatures of $50^{\circ} \mathrm{C}, 55^{\circ} \mathrm{C}, 60^{\circ} \mathrm{C}$ and $65^{\circ} \mathrm{C}$.

Approximately, $5 \mathrm{ml}$ sample was taken from the reactor after $10,20,40,60,90,120,180$ and 240 minutes reaction time intervals. Each sample was taken in a centrifuge tube and iced to stop the reaction. The product was separated from the mixture and the free fatty acid content of the product plus that of the feedstock was determined using the AOCS Ca 5a-40 procedure [24] from Eqn 1. The\% FFA conversion was determined from Eqn. (2)

$$
\text { FFA value }=\frac{\text { Titre value } \times 0.1 \mathrm{~N} \mathrm{NaOH} \times 28.2}{\text { Weight of sample }}
$$

\subsection{PFAD Fatty acid Methyl Ester (FAME) Properties Analyses}

The properties of the PFAD FAME were assessed subsequently using ASTM methods. The kinematic viscosity of PFAD FAME was determined employing the CannonFenske routine viscometer for liquids that are transparent following the ASTM D445 method. The density of FAME was determined utilizing pycnometer. The measurement steps were done following the ASTM D4052 method. The pour and cloud point of PFAD FAME were determined employing the Cloud and Pour Point Tester, Petrotest. The pour point was performed using ASTM D97 standard method while the cloud point test was by ASTM D2500 standard method. The flash point was performed by means of the Flash Point Tester, Petrotest PM4 following ASTM D93 method. Calorific value of PFAD FAME was performed by employing Oxygen Bomb
FFA value of feedstock

Calorimeter, Parr following the ASTM D240 procedure. The carbon residue was estimated utilizing the Conradson Carbon Residue apparatus according ASTM D189 method. The water content was measured by Coulometric KF titration method following the ASTM D6304 specification. The acidity of the FAME was evaluated by titration following the ASTM D974 method while the copper strip corrosion test followed the ASTM D130 method.

\section{Results and Discussion}

\subsection{Kinetic Model}

The esterification reaction that occurred between free fatty acid of the PFAD and methanol catalyzed with acid is relatively a simple reversible reaction represented below: 
<smiles>[R]C(=O)O</smiles>

In general, solid acid catalyst is insensitive and favourable to low quality feedstock with high FFA like the PFAD. The mechanism (pathway) of the acidic sites (Brønsted) of the catalyst for the PFAD esterification consists of the following steps as depicted in Figure 2. (a) TheBrønsted acidic sites of the carbon based catalyst (sulfonated glucose acid catalyst) begins the reaction by providing a proton to protonate the carbonyl carbon of the FFA molecules. (b) This is followed then by the nucleophilic attack from the hydroxyl group of the methanol $\left(\mathrm{CH}_{3}-\mathrm{OH}\right)$ on carbonium ion to form tetrahedral intermediate (I) specie. (c) Is the rearrangement of the proton of hydroxyl of the methanol which was then moved to the carbonyl oxygen of the FFAs. (d) The tetrahedral intermediate (II) specie was dehydrated forming one molecule of water and a protonated ester, and finally (e), the proton of the tetrahedral intermediate (II) specie was moved to the $\mathrm{SO}_{3}$ to restore the Brøntsted active sites $\left(\mathrm{SO}_{3} \mathrm{H}\right)$ and fatty acid methyl esters (FAME) were formed [26, 27].

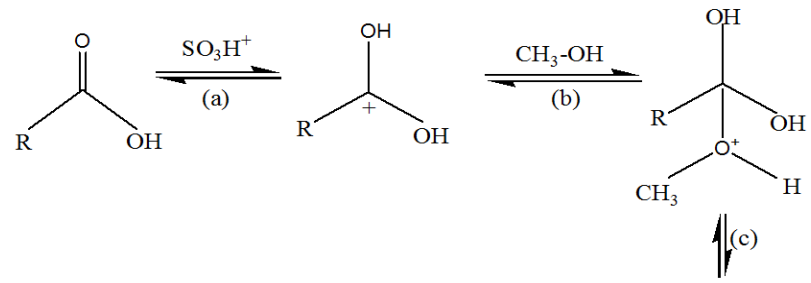

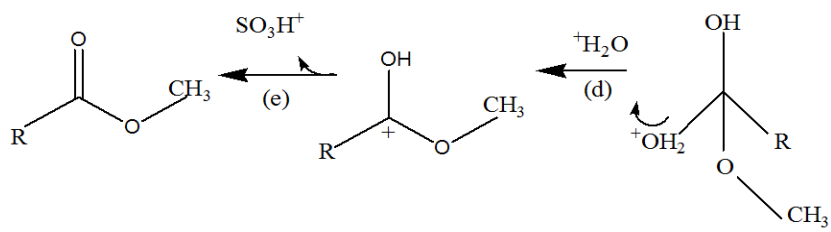

Figure 2. Stepwise reaction mechanism involving acidic sites catalyzed esterification of carbon based catalyst and PFAD.

The data used for the kinetic study were obtained from the calculated percentage FFA of the PFAD converted to FAME. The percentage FFA conversion from $50^{\circ} \mathrm{C}$ to $65^{\circ} \mathrm{C}$ are shown in Figure 3.

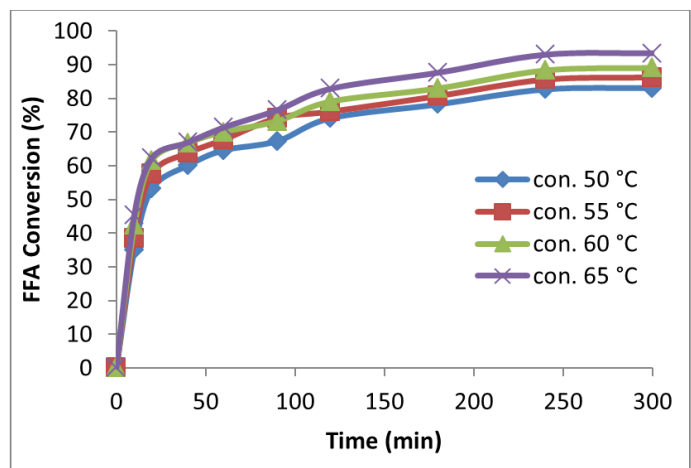

Figure 3. Influence of reaction temperature on conversion of free fatty acid of PFAD.<smiles>[R]C(=O)OC</smiles>

The results showed that the reactions were fast and achieved about $60 \%$ conversion after 20 minutes and became slower as the time of reaction increased up to 240 minutes. The graph also indicated that temperature has a marginal influence on fatty acid conversion within the chosen temperature range of $50^{\circ} \mathrm{C}$ to $65^{\circ} \mathrm{C}$. The purpose of studying reaction kinetics was to develop kinetic models that properly fit the experimental data and this was achieved by trial and error method. All kinetic models depend on the nature of the data utilized in the research work and can be concentration based and fractional weight based kinetics model [28]. The assumptions made to the kinetic model to fit the experimental data in this study were:

1. The behavior of the esterification reaction follows pseudo-homogeneous.

2. The reverse reaction was neglected, since methanol was used in excess.

\subsubsection{First Order Kinetic Model Test}

Pseudo-homogeneous model of first order corresponding to the reaction in Equation 3 can be described as follow:

$$
-\mathrm{r}_{\mathrm{A}}=-\frac{\mathrm{dC}_{\mathrm{A}}}{\mathrm{dt}}=\mathrm{kC}_{\mathrm{A}} \mathrm{C}_{\mathrm{B}}
$$

Where $-r_{A}$ is the rate of reaction of FFA, $C_{A}$ is the concentration of FFA, $C_{B}$ is the concentration of methanol while $\mathrm{k}$ stands for the rate constant for the forward reaction. Since excess methanol was used, $C_{B}$ is assumed to be fixed. Hence the reaction rate can be expressed as pseudo first order.

$$
\left(-r_{A}\right)=k C_{A}
$$

Equation 3 can be written as:

$$
\left(-r_{A}\right)=-\frac{d C_{A}}{d t}
$$

Subsituting equation 6 to 5 gives:

$$
\begin{gathered}
-\frac{d C_{A}}{d t}=k C_{A} \\
\frac{d C_{A}}{d t}=-k d t
\end{gathered}
$$

Integrating equation 7 becomes:

$$
\begin{gathered}
\ln C_{A}-\ln C_{A o}=k t \\
\ln \frac{C_{A o}}{C_{A}}=k t
\end{gathered}
$$

From equation 8 graph of $\ln \frac{C_{A o}}{C_{A}}$ against time were plotted at various temperatures, where $\mathrm{k}$ which is the slope is the reaction rate constant. Figure 4 shows the graph of $\ln \frac{C_{A o}}{C_{A}}$ versus time at various chosen temperatures of reaction. 


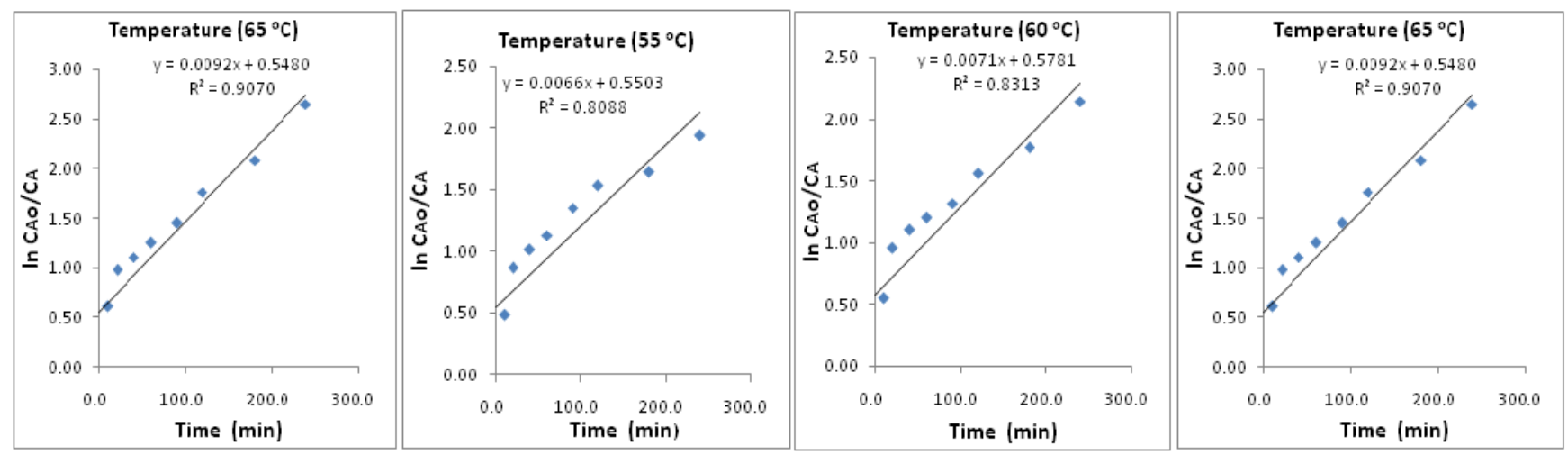

Figure 4. Graphs of $\ln \frac{C_{A o}}{C_{A}}$ versus time for pseudo first order at temperatures of $50,55,60$ and $65^{\circ} \mathrm{C}$.

The experimental data did not correlate well with the pseudo first order model because the regression coefficients $\mathrm{R}^{2}$ were not quite good (below 0.9 ) except for that of $65^{\circ} \mathrm{C}$ that was up to 0.9 (Figure 4). Inaddition, the straight line plot is expected to pass through to the origin for first order model [29].

\subsubsection{Second Order Kinetic Model Test}

The rate equation corresponding to the reaction in equation 3 for irreversible bimolecular second order reaction is:

$$
-r_{A}=-\frac{d C_{A}}{d t}=-\frac{d C_{B}}{d t}=k C_{A}
$$

Where $C_{A}$ and $C_{B}$ represent the concentration of PFAD free fatty acid and methanol, respectively and $\mathrm{k}$ stands for the rate constant of the reaction in the forward direction.

However, considering the irreversible bimolecular second order reaction with equimolar reactant concentration, the assumption behind this model is that reactants are used in stoichiometric amount $(\mathrm{CA}=\mathrm{CB})$. Hence, from equation 9, the rate equation can be expressed as;

$$
-\mathrm{r}_{\mathrm{A}}=-\frac{\mathrm{dC}_{\mathrm{A}}}{\mathrm{dt}}=\mathrm{kC}_{\mathrm{A}}^{2}
$$

$$
-\frac{d C_{A}}{C_{A}^{2}}=k d t
$$

Integration of equation 10 gives:

$$
\frac{1}{C_{A}}=\frac{1}{C_{A O}}+k t
$$

From equation 11, graphs of $\frac{1}{C_{A}}$ versus time were plotted at each temperature, where $\mathrm{k}$ represent rate constant and $\frac{1}{C_{A O}}$ is the intercept.

Figure 5 depicts the graphs of $\frac{1}{C_{A}}$ versus time for the selected temperatures of reaction. The experimental data correlated quite well with the equimolar model having $\mathrm{R}^{2}$ (regression coefficient) greater than 0.9 , although in the esterification reaction excess methanol was used. According to the report by Coker [29], the equimolar kinetic model was chosen because the data available for the kinetic model was concentration (FFA value) which complies with the experimental data and graphical plots. The reaction rate constants at various reaction temperatures at optimum operating conditions from Figure 5 plots are $2 \times 10^{-4}, 2.47 \mathrm{x}$ $10^{-4}, 3.04 \times 10^{-4}$ and $5.33 \times 10^{-4}$ g. $\mathrm{mg}^{-1} \mathrm{~min}^{-1}$.
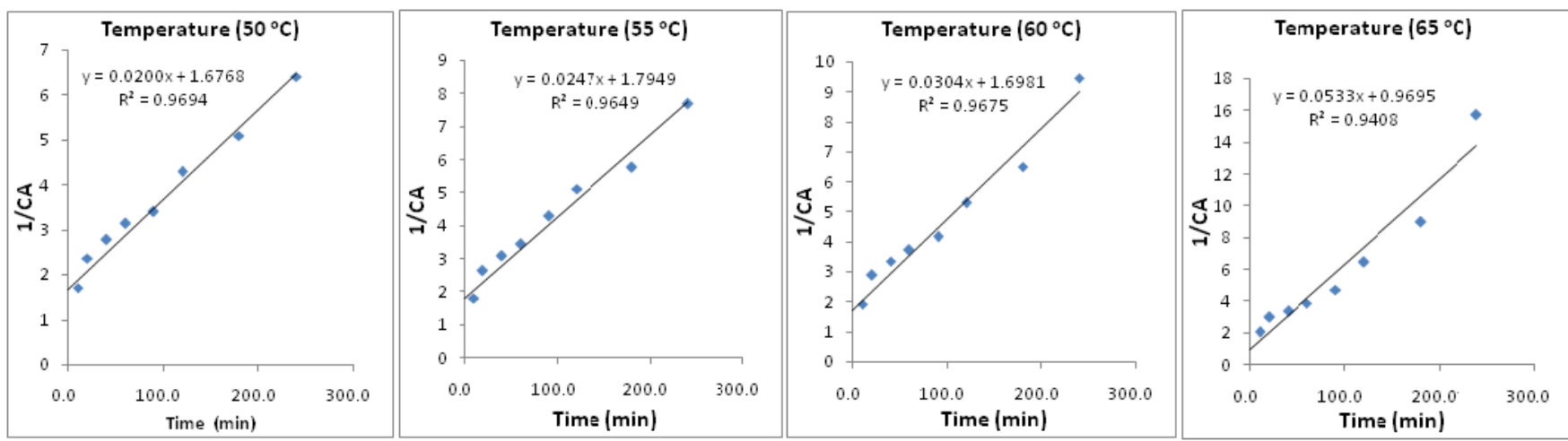

Figure 5. Graphs of $1 / C_{A}$ versus time for second order at temperatures of $50,55,60$ and $65^{\circ} \mathrm{C}$.

As indicated in Table 2, the esterification rate constant from the kinetic models increased with increase in temperature. The rate constant increased from $2 \times 10^{-4}$ to $5.33 \times 10^{-4}$ as the temperature of reaction was increased from
50 to $65^{\circ} \mathrm{C}$. The results indicate that reaction temperature positvely influences the rate of esterification of the PFAD to FAME. 
Table 2. Rate constant at selected temperature for the FFA esterification.

\begin{tabular}{lll}
\hline Temperature $\left({ }^{\circ} \mathbf{C}\right)$ & Rate constants, $\mathbf{k}\left(\mathrm{g} \cdot \mathbf{m g}^{-1} \mathbf{~ m i n}^{-1}\right)$ & $\mathbf{R}^{2}$ \\
\hline 50 & $2.0 \times 10^{-4}$ & 0.9694 \\
55 & $2.47 \times 10^{-4}$ & 0.9649 \\
60 & $3.04 \times 10^{-4}$ & 0.9675 \\
65 & $5.33 \times 10^{-4}$ & 0.9408 \\
\hline
\end{tabular}

\subsection{Activation Energy (Ea) Determination}

Activation energy (Ea) is expressed as the energy barrier reactants have to prevail over in order to react [30] and this was determined using Arrhenius equation. Arrhenius equation relates how temperature influences a reaction at equilibrium state represented as:

$$
k=A e^{\frac{-E a}{R T}}
$$

Where $\mathrm{k}$ stands for rate constant, A represents the pre-exponential factor or frequency factor, Ea represents energy of activation, $\mathrm{T}$ stands for absolute temperature while $\mathrm{R}$ stands for the universal gas constant. $\mathrm{ln} \mathrm{k}$ versus $\frac{1}{T}$ graph was plotted and the gradient was $-\frac{E a}{R}$ as indicated in Figure 6 .

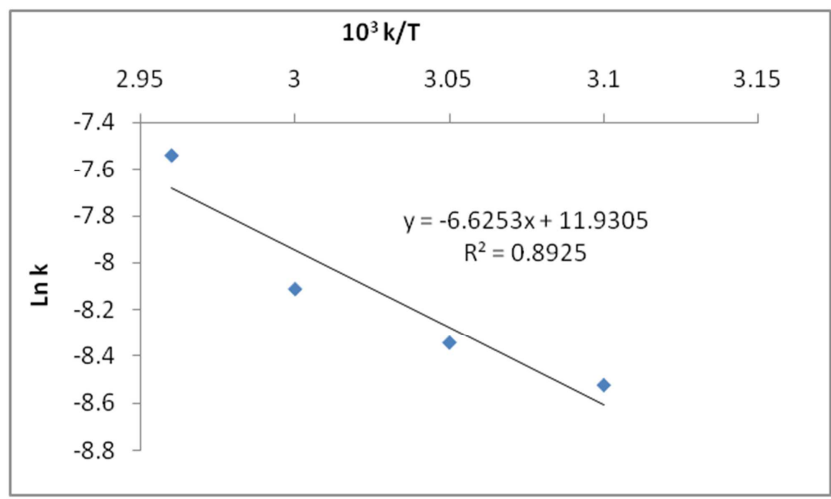

Figure 6. Graph of $\ln k$ vs $1 / T$.

The activation energy was calculated to be $55.08 \mathrm{kJmol}^{-1}$ with $\mathrm{R}^{2}$ of 0.893 . The calculated activation energy is in agreement with the conversion results. The activation energy result shows the amount of energy barrier that the reactants have to surmount inorder to react [30] with the aid of the optimized sulfonated glucose catalyst in the esterification. The catalyst influences the reaction rate enabling the formation of the product, thus leading to lower activation energy than the uncatalyzed reaction [29].

This result is also comparable to reported activation energy of $56 \mathrm{kJmol}^{-1}$ and $57 \mathrm{kJmol}^{-1}$ for LO (lanthanum oxide) and HZSM (zeolite) catalyzed esterification of FFA (oliec acid) with methanol, respectively [31]. Berrios et al. [32] reported $51 \mathrm{kJmol}^{-1}$ activation energy for FFA esterification of sunflower oil with $5 \% \mathrm{H}_{2} \mathrm{SO}_{4}$ concentration. The activation energy was better compared to $145 \mathrm{kJmol}^{-1}$ reported by Sawitri et al. [20] for the esterification of FFA in PFAD with sulfated zirconia catalyst. This result also shows that the prepared catalyst was much more active than the sulfated zirconia catalyst for esterification of PFAD feedstock to biodiesel.

\subsection{Fuel Properties of PFAD Biodiesel}

Some relevant fuel characteristics of the PFAD FAME were determined, as shown in Table 3, in accordance with the ASTM biodiesel standard [33], which are kinematic viscosity $(40 \circ \mathrm{C})$, density, pour point, flash point, cloud point, copper strip corrosion, total acid number water content as well as calorific value.

The kinematic viscosity of the PFAD FAME (biodiesel) fell within the prescribed ASTM D 6751 specifications and a little bit higher for EN 14214 [34] specifications. The kinematic viscosity expresses the flow behavior and the possibility of the fluid to be deformed by tensile or shear stress. It is also a relevant parameter for fuel atomisation and distribution. The density of PFAD FAME was within both the specifications for ASTM and EN $\left(860-900 \mathrm{~kg} / \mathrm{m}^{3}\right)$ standards. Flash point of the PFAD FAME was much better than diesel fuel and was above both fuel minimum standards, as expected. Flash point is known as the ignition temperatue of the biodiesel when exposed to a spark or flame. This property is usually given consideration in safe handling and storage of fuels.

Table 3. Fuel properties of PFAD fatty acid methyl ester.

\begin{tabular}{lllll}
\hline Properties & PFAD FAME & Diesel fuel [35] & ASTM D 6571 & EN 14214 \\
\hline Density $\left(\mathrm{kg} / \mathrm{m}^{3}\right)$ at $15^{\circ} \mathrm{C}$ & 865 & 850 & $860-900$ & $860-900$ \\
Kinematic viscosity $\left(\mathrm{mm}^{2} / \mathrm{s}\right)$ at $40^{\circ} \mathrm{C}$ & 5.46 & 2.6 & $1.9-6.0$ & $3.5-5.0$ \\
Flash point $\left({ }^{\circ} \mathrm{C}\right)$ & 140 & 68 & $130 \mathrm{~min}$ & $120 \mathrm{~min}$ \\
Pour point $\left({ }^{\circ} \mathrm{C}\right)$ & 15 & -15 & -15 to 10 & - \\
Cloud point $\left({ }^{\circ} \mathrm{C}\right)$ & 16 & -10 & -3 to 12 & - \\
Calorific value $(\mathrm{MJ} / \mathrm{kg})$ & 42.1 & $42-46$ & $>35$ & - \\
Copper strip corrosion $\left(50^{\circ} \mathrm{C}, 3 \mathrm{~h}\right)$ & $1 \mathrm{a} *$ & $1 \mathrm{a}$ & No. 3 max. & -1 min. \\
Water content $(\%$ vol.) & 0.0092 & 0.02 & 0.03 max & 0.50 max \\
Total acid number & 0.782 & - & 0.80 max & - \\
$(\mathrm{mgKOH} / \mathrm{g})$ & & & $0.05 \max$ & \\
Carbon residue $(\% \mathrm{wt})$ & 0.05 & 0.17 & & \\
\hline
\end{tabular}

*: ASTM copper strip colored reproduction classification description, '1a' signifying slight tarnish (light orange, almost same as freshly polished strip)

On the contrary, the PFAD FAME displayed a high cloud and pour point when compared to the ASTM standard and diesel fuel temperatures. These increased values are attributed to the characteristics of the PFAD to comprise of high amount free fatty acid. These parameters indicate the minimum temperature for the biodiesel usage. The main discrepancy 
between the properties is that at cloud point temperature, fuel can still be utilized whereas at pour point temperature it becomes solidified and unusable. The calorific value of the FAME was evaluated to be $42.1 \mathrm{MJ} / \mathrm{Kg}$ and this falls within the ASTM D 6751 specification for smooth operating engine.

The acid value was below the maximum ASTM specification although a little bit higher than the European maximum specified value. However, the copper stip corrosion result for the PFAD FAME was within the specifications for EN and ASTM. The water content of the PFAD biodiesel was below the maximum ASTM specification indicating that the biodiesel will neither cause corrosion of the fuel system components nor reduce the heat of combustion.

\section{Conclusions}

The kinetics of the modified sulfonated glucose catalyzed esterification of PFAD to FAME was successfully studied in a conventional reflux batch reactor. The kinetic data for the PFAD FFA esterification can be best described using the bimolecular model (equimolar model) second order reaction. The activation energy was found to be $55.08 \mathrm{kJmol}^{-1}$ which is comparable to other esterification reaction and quite low (better) to $144.92 \mathrm{kJmol}^{-1}$ obtained from using sulfated zirconia catalyst for PFAD esterification. The The prepared catalyst was able to esterify the high FFA feedstock achieving $>$ 93\% conversion and $91.87 \%$ FAME yield under optimized operating conditions from previous study by Kefas et al. [24]. The results of the fuel properties were in good agreement with ASTM standards except for low temperature properties which were slightly above the standard. Activation energy shows that the prepared catalyst is efficient for converting high FFA feedstock to biodiesel.

\section{Acknowledgements}

This research work received support financially by Universiti Putra Malaysia through research grant GP-IPS/2016/9485900.

\section{References}

[1] Nata I. F., Putra M. D., Irawan C. and Lee C-K. (2017). Catalytic performance of sulfonated carbon-based solid acid catalyst on esterification of waste cooking oil for biodiesel production, J. Environ. Chem. Eng. 5: 2171-2175.

[2] Lopez D. E., Goodwin J. G., Jr., Bruce D. A. and Furuta S. (2008). Esterification and transesterification using modified-zirconia catalysts, Appl. Catal. A, 339: 76-83.

[3] Liu Y., Lotero E., Goodwin J. G. and Jr., Mo X. (2007). Transesterification of poultry fat with methanol using Mg-A1 hydrotalcite derived catalysts, Appl. Catal. A, 331: 138-148.

[4] Schuchardt U., Sercheli R. and Vargas R. M. (1998). Transesterification of vegetable oils: a review, J. Brazillian Chem. Soc., 9: 199-210.

[5] Srivastava A. and Prasad R. (2000). Triglycerides-based diesel fuels, Renew. Sust. Energy Rev., 4: 111-133.

[6] Ng J. H., Ng H. K. and Gan S. (2010). Advances in biodiesel fuel for application in compression ignition engines, Clean Tech. Environ. Policy, 12: 459-493.

[7] Atadashi I. M., Aroua M. K., Abdul Aziz A. R. and Sulaiman N. M. N. (2012). Production of biodiesel using high free fatty acid feedstocks, Renew. Sust. Energy Rev., 16: 3275-3285.

[8] Chongkong S., Tongurai C. and Chetpattananondh P. (2009). Continuous esterification for biodiesel production from fatty acid distillate using economical process, Renew. Energy, 34: 1059-1063.

[9] Kawentar W. A. and Budiman A. (2013). Synthesis of biodiesel from second-used cooking oil, Energy Procedia, 32: 190-199.

[10] Mujeli M., Kefas H. M., Shitu A. and Ayuba I. (2016).. Optimization of biodiesel production from crude cotton seed oil using central composite design. Advances in Biochemistry, 4: $94-100$.

[11] Oils \& Fats International. Indonesia, Malaysia palm oil output projected to grow in 2018. https://www.ofimagazine.com/news/indonesia-malaysia-palmoil-output-projected-to-grow-in-2018 (accessed December 2018).

[12] Malaysian Palm Oil Board. (2010).www.mpob.gov.my.

[13] Chongkhong S., Tongurai C., Chetpattananondh P. and Bunyakan C. (2007). Biodiesel production by esterification of palm fatty acid distillate, Biomass Bioenergy, 31: 563-568.

[14] Nakpong P. and Woothikanokkhan S. (2010). High free fatty acid coconut oil as a potential feedstock for biodiesel production in Thailand, Renew. Energy, 35: 1682-1687.

[15] Chin, L. H., Abdullah A. Z. and Hameed B. H. (2012). Sugar cane bagasse as solid catalyst for synthesis of methyl esters from palm fatty acid distillate, ChemEng J. 183: 104-107.

[16] Furuta S., Matsuhashi H. and Arata K. (2004). Biodiesel fuel production with solid superacid catalysis in fixed bed reactor under atmospheric pressure, Catal. Comm., 5: 721-723.

[17] Cheng Y., Feng Y., Ren Y., Liu X., Gao A., He B., Yan F. and Li J. (2012). Comprehensive kinetic studies of acidic oil continuous esterification by cation-exchange resin in fixed bed reactors, Bioresour. Technol., 113: 65-72.

[18] Rattanaphra D., Harvey A. P., Thanapimmetha A. and Srinophakun P (2011). Kinetic of myristic acid esterification with methanol in the presence of triglycerides over sulfated zirconia, Renew. Energy, 36: 2679-2686.

[19] Pappu V. K. S., Yanez A. J., Peereboom L., Muller E., Lira C. T. and Miller D. J. (2011) A kinetic model of the Amberlyst-15 catalyzed transesterification of methyl stearate with n-butanol, Bioresour. Technol., 102: 4270-4272.

[20] Sawitri D. R., Budiman S. and Budiman A. (2017). Kinetics study of free fatty acids esterification for biodiesel production from palm fatty acid distillate catalysed by sulfated zirconia, ARPN J. Eng. Appl. Sci., 11: 9951-9957.

[21] Shu Q., Zhang Q., Xu G., Nawaz Z., Wang D. and Wang J. (2009). Synthesis of biodiesel from cottonseed oil and methanol using a carbon-based solid acid catalyst, Fuel Process. Technol., 90: 1002-1008. 
[22] Alhassan F. H., Yunus R., Rashid U., Sirat K., Islam A., H. V. Lee, et al. (2013). Production of biodiesel from mixed waste vegetable oils using ferric hydrogen sulphate as an effective reusable heterogeneous solid acid catalyst, ApplCatal A-Gen. 456: $182-187$.

[23] Zong M. H., Duan Z. Q., Lou W. Y., Smith T. J. and Wu H. (2007). Preparation of sugar catalyst and its use for highly efficient production of biodiesel, Green Chem. 9: 434-437.

[24] Kefas H. M., Yunus R., Rashid U. and Taufiq-Yap Y. H. (2018). Modified sulfonation method for converting carbonized glucose into solid acid catalyst for the esterification of palm fatty acid disstillate, Fuel, 229: 68-78.

[25] Shuit H. S. and Tan S. H. (2014). Feasibilty study of various sulphonation methods for transforming carbon naotubes into catalysts for the esterification of palm fatty acid distillate, Energy Conserv. Manage. 88: 1283-1289.

[26] Guo F., Xiu Z. L. and. Liang Z. X. (2012). Synthesis of biodiesel from acidified soybean soapstock using a lignin-derived carbonaceous catalyst, Appl. Energy, 98: 47-52.

[27] Al-Jaberi S. H. H., Rashid U., Al-Doghachi F. A. J., Alsultan A. and Taufiq-Yap Y. H. (2017). Synthesis of $\mathrm{MnO}-\mathrm{NiO}-\mathrm{SO}_{4}{ }^{-2} / \mathrm{ZrO}_{2}$ solid acid catalyst for methyl ester production from palm fatty acid distillate, Energy Conserv. Manage, 139: 166-174.

[28] Habib N. S. H. A., Yunus R., Rashid U., Taufiq-Yap Y. H., Abidin Z. Z., Syam A. M. and Irawan S. (2014). Transesterification reaction for synthesis of palm-based ethylhexyl ester and formulation as base oil for the synthesis of drilling fluid, J. Oleo Sci., 63: 497-506.

[29] Coker A. K. (2000). Modelling of chemical kinetics and reactor design, Gulf Publishing Company, Houston, Texas.

[30] Lavenspiel O. (1999). Chemical reaction engineering, John Wiley and Sons Inc., United States.

[31] Vieira S. S., Magriotis Z. M., Santos N. A. V., Saczk A. A., Hori C. E. and Arroyo P. A. (2013). Biodiesel production by free fatty acid esterification using lanthaum $\left(\mathrm{La}^{3+}\right)$ and HZSM-5 based catalysts, Bioresour. Technol., 133: 248-255.

[32] Berrios M., Siles J., Martin M. and Martin A. (2007). A kinetic study of the esterification of free fatty acids (FFA) in sunflower oil, Fuel, 86: 2383-2388.

[33] Kefas H. M., Yunus R., Rashid U. and Taufiq-Yap Y. H. (2019). Enhanced biodiesel synthesis from palm fatty acid distillate and modified sulfonated glucose catalyst via an oscillation flow reactor system. J. Environ. Chem. Eng. 7: 102993.

[34] European Committee for Standardization (CEN). (2012) EN 14214 Automotive fuels diesel-Fatty acid methyl esters (FAME) - Requirements and test methods. CEN, Brussels, Belgium.

[35] Tiwari A. K., Kumar A., and Raheman H. (2007). Biodiesel production from Jatropha oil (Jatrophacurcas) with high free fatty acids: an optimized process, Biomass Bioenergy, 31: 569-575. 